\title{
A Survey of Canadian, Student-Run Campus Emergency Medical Response Teams
}

\author{
Evan A. Formosa, Lexie Grainger, Austyn D. Roseborough, Andrea M. Sereda, \\ Lauren E. Cipriano
}

Keywords: first responders; prehospital emergency care; students; universities; volunteers

Citation (AMA Style): Formosa EA, Grainger L, Roseborough AD, Sereda AM, Cipriano, LE. A Survey of Canadian, Student-Run Campus Emergency Medical Response Teams. J Coll Emerg Med Serv. 2020; 3(2):

11-19. https://doi.org/10.30542/JCEMS.2020.03.02.04

Electronic Link: https://doi.org/10.30542/JCEMS.2020.03.02.04

Published Online: December 31, 2020

Published in Print: December 31, 2020 (Volume 3: Issue 2)

Copyright: (C) 2020 Formosa, Grainger, Roseborough, Sereda \& Cipriano. This is an OPEN ACCESS article distributed under the terms of the Creative Commons Attribution 4.0 International (CC BY 4.0) License, which permits unrestricted use, distribution, and reproduction in any medium, provided the original author and source are credited. The full license is available at: www.creativecommons.org/licenses/by/4.0/ 


\title{
A Survey of Canadian, Student-Run Campus Emergency Medical Response Teams
}

\author{
Evan A. Formosa, MSc; Lexie A. Grainger, MD; Austyn D. Roseborough, MSc; Andrea M. Sereda, MD; \\ Lauren E. Cipriano, PhD
}

\begin{tabular}{|c|}
\hline ABSTRACT \\
\hline $\begin{array}{l}\text { Objectives: Campus emergency medical response teams (CEMRTs) are organizations on university/ } \\
\text { college campuses who respond to medical emergencies. This study sought to determine the } \\
\text { prevalence of these CEMRTs across Canada and characterize their training, operations and call } \\
\text { volume. Methods: All identified Canadian CEMRTs were invited to participate in an online survey } \\
\text { between February and April 2018. The survey requested information on years of operation, call } \\
\text { volume, personnel, training level, medical direction, operations, funding, system activation, and } \\
\text { mode of response. Results: Twenty-three CEMRTs completed the survey. Ten teams ( } 43 \%) \text { provide } \\
\text { on-call service } 24 \text { hours per day, } 7 \text { days per week. Nine teams respond to }<100 \text { calls/year, } 11 \text { teams to } \\
\text { 100-500 calls/year, and three teams to }>500 \text { calls/year. Teams ranged in size from } 16 \text { to } 75 \text { responders } \\
\text { (mean } 41.7 \text { [SD 16]) and all were student volunteers. Training level varied, with } 48 \% \text { of CEMRTs } \\
\text { being trained at the First Responder level and } 48 \% \text { having physician oversight. An automated } \\
\text { external defibrillator was carried by } 91 \% \text { of CEMRTs and high-volume teams tended to carry more } \\
\text { symptom relief medication. Conclusions: Many CEMRTs are operating throughout Canada but } \\
\text { with significant variation in many aspects of operation. Further studies characterizing the types of } \\
\text { incidents CEMRTs respond to are needed to better understand their role on Canadian campuses. }\end{array}$ \\
\hline
\end{tabular}

Keywords: first responders; prehospital emergency care; students; universities; volunteers

Corresponding Author and Author Affiliations: Listed at the end of this article.
$\mathrm{U}$ niversity and college campuses are diverse communities. Campus communities are high-population-density, nearly city-sized groups of predominantly healthy young adults. Others on campuses include faculty, staff, and community visitors who may be more representative of the general population. Campuses may be located within the fabric of a city or they may

Evan Formosa, MSc is a medical student at New York Medical College in Valhalla, New York, USA and currently serves as the Canadian Regional Coordinator for the National Collegiate Emergency Medical Services Foundation (NCEMSF). He was formerly the Executive Director of the Western University Student Emergency Response Team in London, Ontario, Canada (2013-2014) and responded with the organization for 6 years (2011-2017). Lexie Grainger, MD is a family physician at Western University in London, Ontario, Canada. She responded with the Western University Student Emergency Response Team for 5 years (2011-2016) and serves as one of the medical directors (2018-present). Austyn Roseborough, MSc is an MD/PHD student at the Schulich School of Medicine and Dentistry at Western University in London, Ontario, Canada. She responded with the Western University Student Emergency Response Team for 3 years (2016-2019) and serves in a training capacity with the team (2019-present) Andrea Sereda, MD is a family and emergency physician working at the London InterCommunity Health Centre in London, Ontario, Canada and is an Adjunct Professor with the department of Family Medicine at the Schulich School of Medicine and Dentistry. She responded with the Western University Student Emergency Response Team for 7 years (20002007) and serves as one of the medical directors (2007-present). Lauren Cipriano, $\mathrm{PhD}$ is an Associate Professor in Management Science at the Ivey Business School and an Associate Professor in the Department of Epidemiology and Biostatistics at the Schulich School of Medicine and Dentistry at Western University in London, Ontario, Canada. She responded with the Western University Student Emergency Response Team for 6 years (1999-2005) and she currently provides assistance with training and support to leadership. be a distinct self-contained geographic region. For self-contained campus communities, the on-campus population at night may be smaller, generally consisting of students living in residence buildings. Often times the students living on campus are living independently for the first time and are simultaneously exposed to new social and educational stressors. Compared to other populations, undergraduate students have higher levels of alcohol use, ${ }^{1}$ are more likely to participate in binge drinking activities, ${ }^{2-4}$ and are more likely to have other high-risk behaviours which make them more prone to injury. ${ }^{5,6}$ As a result, this population can have high rates of emergency medical services use. ${ }^{7,8}$

Campus emergency medical response teams (CEMRTs), also called collegiate-based emergency medical systems, ${ }^{9}$ are organizations of staff or volunteer responders, familiar with the campus community and its particular geography, trained in first aid that respond to medical emergencies with high-value first response care. ${ }^{9-13}$ Various levels of medical training, offered by multiple certifying agencies, are available to CEMRTs operating in Canada. CEMRT training can range from basic first aid to courses targeted to professional first responders. Common training levels are described in Table 1. Some CEMRTs train to the Emergency Medical Responder (EMR) level, which requires demonstration of specific competencies as defined in the National Occupational Competency Profiles set by the Paramedic Association of Canada. ${ }^{14}$ EMR is considered below the level of a primary care paramedic (PCP), the designation that 
is required to work for a regional emergency medical service. Certification as a PCP requires a college degree, and often candidates must pass a provincial certifying exam consistent with their greater scope of practice and responsibility. ${ }^{14}$ With medical direction from a physician, some CEMRTs may perform basic delegated medical acts, such as administration of epinephrine for anaphylaxis and albuterol for asthma exacerbation, but this is not required for basic operation. ${ }^{15}$

CEMRT responders are located on campus, allowing for quick response to life-threatening emergencies, assistance of local PCPs, and management of minor incidents that may not require a PCP. ${ }^{11,12}$ CEMRTs also triage calls with in-person assessment to identify those that require paramedic response, direction to urgent care, and/or direction to campus health services for primary care or mental health care, helping to reduce the burden on local emergency services. ${ }^{10-12,16}$ Further, CEMRTs are able to build trusting relationships with their community, which may increase reporting of life-threatening but stigmatized behaviours. ${ }^{16}$

An often-overlooked aspect of emergency response to university and college campuses is the complexity of the campuses and the buildings. Buildings are often clustered together, sometimes requiring navigation through one building to reach another. Buildings are often known by names or nicknames rather than street addresses, which may result in callers providing confusing or incomplete information for emergency services. Familiarity with the networks of connected campus buildings is essential for the quick location of an ill or injured person, which may be outcome-determining in some life-threatening emergencies.

Two previous surveys characterizing North American campusbased emergency medical services were published in $1996^{13}$ and
$2006^{9}$ using different methods to identify CEMRTs in operation. King et al. ${ }^{13}$ identified 234 CEMRTs across the U.S. and Canada, the majority of which used paid professional staff (62\%) for some or all response duties. Fisher et al. ${ }^{9}$ used the National Collegiate Emergency Medical Services Foundation (NCEMSF) registry identifying 145 CEMRTs, including one in Canada, 73\% of which were exclusively volunteer-based. Due to the lack of research within Canada specifically, the objectives of this study were to determine the prevalence of CEMRTs across Canada, to characterize the operations, range of training level, and call volume of Canadian CEMRTs, and to gain an understanding of their role within their community emergency medical service (EMS) systems.

\section{Methods}

\section{Study population}

Teams were identified through the Association of Campus Emergency Response Teams of Canada (ACERT), the National Collegiate Emergency Medical Services Foundation (NCEMSF), and the study authors' prior knowledge. The ACERT website listed 25 unique teams, 13 of which were also listed on the NCEMSF website. An additional five teams were identified by the authors, three of which were located in Nova Scotia and two in British Columbia. All 30 known Canadian campus emergency response teams were contacted by email using the teams' official email address published on publicly available team websites. Between February and April 2018, teams were sent a maximum of three reminder emails. All survey respondents were required to confirm that they were authorized to disclose the requested information for their organization. Consent for follow-up with survey respondents was obtained in the event that clarification of survey responses was required.

\section{Table 1: Summary of Canadian First Aid training courses ${ }^{17}$}

\begin{tabular}{|c|c|c|c|}
\hline & SFA with CPR & First Responder & Emergency Medical Responder \\
\hline Course length & 13-14 hours & 40 hours & 80-120 hours \\
\hline Primary use & $\begin{array}{l}\text { Occupational requirements or } \\
\text { home emergencies }\end{array}$ & $\begin{array}{l}\text { Professional first responders (e.g., } \\
\text { police, fire) }\end{array}$ & $\begin{array}{l}\text { Emergency care professionals respon- } \\
\text { sible for initial assessments, safe and } \\
\text { prudent care, and patient transporta- } \\
\text { tion } \\
\text { (e.g., fire and rural EMS) }\end{array}$ \\
\hline $\begin{array}{l}\text { Content of training } \\
\text { course }\end{array}$ & $\begin{array}{l}\text { - Breathing and circulatory } \\
\text { emergencies } \\
\text { - Respiratory arrest } \\
\text { - Cardiac arrest } \\
\text { - Wound care } \\
\text { - Head and spine injuries } \\
\text { - Sudden medical emergencies } \\
\text { - Environmental emergencies }\end{array}$ & $\begin{array}{l}\text { SFA with CPR plus: } \\
\text { - Anatomy and physiology } \\
\text { - Assessment } \\
\text { - Shock } \\
\text { - Hemorrhage and soft tissue } \\
\text { injuries } \\
\text { - Chest, abdominal, and pelvic } \\
\text { injuries } \\
\text { - Crisis intervention } \\
\text { - Reaching, lifting, and extricat- } \\
\text { ing } \\
\text { - Multiple Casualty Incidents }\end{array}$ & $\begin{array}{l}\text { First responder plus: } \\
\text { - Transportation } \\
\text { - Pharmacology } \\
\text { - With Medical Direction: } \\
\text { o Glucometry } \\
\text { o Epinephrine } \\
\text { o Albuterol } \\
\text { o Aspirin } \\
\text { ○tc. }\end{array}$ \\
\hline
\end{tabular}


Table 2: Universities and colleges with campus emergency medical response teams

\begin{tabular}{|c|c|c|c|c|c|c|}
\hline \multirow[b]{2}{*}{ Team } & \multirow[b]{2}{*}{$\begin{array}{c}\text { Year of } \\
\text { inception }\end{array}$} & \multirow{2}{*}{$\begin{array}{c}\text { Number } \\
\text { of student } \\
\text { volunteer } \\
\text { responders }\end{array}$} & \multicolumn{3}{|c|}{ Response during academic year } & \multirow[b]{2}{*}{$\begin{array}{c}\text { Annual call } \\
\text { volume }\end{array}$} \\
\hline & & & 24/7 & $\begin{array}{l}\text { Select on- } \\
\text { call hours }\end{array}$ & $\begin{array}{l}\text { Special } \\
\text { events }\end{array}$ & \\
\hline \multicolumn{7}{|l|}{ West of Ontario (13\%) } \\
\hline University of British Columbia (Okanagan) & 2015 & 70 & X & & $\mathrm{X}$ & $100-500$ \\
\hline University of British Columbia (Vancouver) & 2010 & 30 & & & $\mathrm{X}$ & $100-500$ \\
\hline University of Calgary & 2014 & 40 & & $X$ & $X$ & $<100$ \\
\hline
\end{tabular}

\section{Ontario (70\%)}

Carleton University

$\begin{array}{lccccc}1999 & 45 & X & X & 100-500 \\ 2009 & 40 & & X & X & 100-500 \\ 1998 & 20 & & X & X & <100 \\ 2016 & 22 & X & & X & <100 \\ 1982 & 30 & X & & X & >500 \\ 1986 & 43 & X & & X & >500 \\ 1993 & 23 & X & & X & 100-500 \\ 1988 & 45 & & X & X & 100-500 \\ 2007 & 60 & X & & & 100-500 \\ 2014 & 42 & X & & & 100-500 \\ 2006 & 75 & & & X & N R \\ 1998 & 50 & & & X & 100-500 \\ 1999 & 40 & X & & X & <100 \\ 1989 & 50 & X & & X & >500 \\ 1994 & 28 & & X & & 100-500 \\ 2016 & 60 & & & X & <100\end{array}$

Fanshawe College

Fleming College

Laurentian University

McMaster University

Queen's University

Trent University

University of Guelph

University of Ontario Institute of

Technology - Durham College

University of Ottawa

University of Toronto (St. George)

University of Waterloo

University of Windsor

Western University

Wilfred Laurier University

60

\begin{tabular}{ll}
2017 & 16 \\
2014 & 55 \\
1997 & 50 \\
2016 & 24 \\
\hline
\end{tabular}

$\begin{array}{ccc} & X & <100 \\ & X & <100 \\ X & X & 100-500 \\ X & X & \text { NR }\end{array}$

NR: not reported

\section{Survey development}

The body of the survey collected information about the number of years the team has served their campus community and recent-year call volumes; personnel, staffing, and medical direction; the level of training and equipment carried; and operations, system activation, dispatch, and mode of response. The survey was implemented using the Qualtrics platform (Qualtrics, Provo, UT). The complete survey is provided in the Appendix (available online).

\section{Ethics}

The study was approved by the Western University Health Science Research Ethics board (110066). 


\section{Results}

Twenty-four teams (80\%) responded to the survey. Six teams thought to be in operation did not respond to the survey. Four of these teams were from Ontario, one was from British Columbia, and one from Nova Scotia. One respondent team, Ryerson University Student Emergency Response Team, was no longer in operation, so 23 teams were included in the final analysis. Most CEMRTs who responded to the survey (20/23) were identified through the ACERT and NCEMSF websites. Teams not identified on an association website who responded to the survey were more recently developed, possibly explaining why they may not yet be registered with ACERT or NCEMSF. All Canadian university and college campuses with an active CEMRT that responded to the survey are listed in Table 2.

\section{Demographics and call volume}

Teams were stratified in low-, medium- and high-volume groups based on the average number of calls they received per year (May to April) for 2015/2016 and 2016/2017. The call volume data was visualized, and natural or substantial breaks were identified resulting in a low-volume group with fewer than 100 calls/year and a high-volume group with greater than 500 calls/year. Two teams did not disclose their call volumes and are excluded from stratification by call volume. Seven teams $(30 \%)$ responded to fewer than 100 calls/year, 11 teams (48\%) responded to between $100-500$ calls/year, and three teams (13\%) responded to greater than 500 calls/year (Table 3 ).

Sixteen teams (70\%) were located in Ontario (Table 3). All highvolume teams had been in operation for greater than 25 years whereas two-thirds of low-volume teams had been in operation for less than five years. Teams ranged in size from 16 to 75 active student responders (mean 41.7; standard deviation 16).

\section{Method of dispatch and response}

Of the survey respondents, ten teams (43\%) indicated that they were dispatched when someone dialled 9-1-1 for a medical emergency (Table 3). Twenty teams (87\%), including all teams that were dispatched via 9-1-1, were dispatched via the campus police or security service and 21 teams (91\%) indicated that they were notified of emergency calls by patients or bystanders approaching them at events. Ten teams (43\%) were also dispatched when calls were placed to their team office.

All 23 teams (100\%) responded to calls on foot (Table 3). Four teams (17\%) owned and operated a vehicle which was used for response, four teams (17\%) were driven by campus security, and three teams (13\%) used bicycles.

\section{Training}

Training level varied greatly by team call volume. Low- and medium-volume teams were primarily trained at the First
Responder (FR) level, although some teams trained at the Standard First Aid (SFA) level, a mix of SFA and FR, or a mix of levels that included some members with EMR training (Table 4). One low-volume team reported that some members were trained as PCPs. Of the three high-volume teams, one was trained at the FR level, one at the EMR level, and one at the EMR level with some responders having additional certification in International Trauma Life Support and Advanced Medical Life Support.

Of the responding teams, 11 teams (48\%) had designated Medical Directors with the frequency of medical direction increasing with call volume (Table 4). All but two teams carried an automated external defibrillator (AED), and nineteen teams (83\%) carried oxygen. High-volume teams tended to carry more symptom relief medications. Sixteen teams $(70 \%)$ carried a form of oral glucose, with five teams (22\%) trained and equipped to perform finger stick blood glucose levels; 13 teams (57\%) carried epinephrine; 12 teams (52\%) carried naloxone; nine teams (39\%) carried aspirin (ASA); nine teams (39\%) were able to provide a patient with their own prescribed nitroglycerin spray; four teams (17\%) carried salbutamol/albuterol; and two teams (9\%) carried diphenhydramine. Nitroglycerin spray was carried by one team (4\%) that had team members trained to the PCP level. This team was also the only team able to start intravenous lines. No teams carried any form of pain management medication.

\section{Operations}

During the academic year, September to April, 10 teams (43\%) provided 24/7 on-call response service including all high-volume, most medium-volume, and two low-volume teams (Table 5). Seventeen teams $(74 \%)$ provided medical response services at campus events, including six teams (26\%) that exclusively provided response coverage at campus events and did not provide a general campus on-call response service. Seven teams (30\%) provided oncall response at select times throughout the week, such as from Thursday to Sunday or during an orientation week. Eleven teams (48\%) provided summer services including event coverage and/or on-call response during specified hours.

\section{Leadership and financial management}

Canadian CEMRTs are associated with various entities on campus, including student councils, health services, police, security, and emergency management/health and safety. Eight teams (35\%) indicated that they are affiliated with two or more of the above listed entities (Table 5).

Teams had a variety of funding sources, with most teams relying on multiple sources of funding (Table 5). The most common funding source, used by 15 teams (65\%), was a student fee, in which all university or college students pay a fee in their tuition that goes directly to the campus response team. The second most common source of financial support, used by nine teams (39\%), was selffunding through teaching first aid courses to the university and 
Table 3: Demographics, dispatch method, and response method of campus emergency medical response teams stratified by call volume

\begin{tabular}{lcccc}
\hline & Total & $\begin{array}{c}\text { Low volume } \\
(\leq \mathbf{1 0 0} \text { calls/year })\end{array}$ & $\begin{array}{c}\text { Medium volume } \\
(\mathbf{1 0 0 - 5 0 0} \text { calls/year })\end{array}$ & $\begin{array}{c}\text { High volume } \\
(\mathbf{> 5 0 0} \text { calls/year })\end{array}$ \\
\hline Number of teams & 23 & 7 & 11 & 3
\end{tabular}

\section{Call volume}

Median (IQR) [Range]

$172(49-412)$

$30[0-75]$

$90[114-460]$

$771[649-892]$

Mean (SD)

$254(260)$

$31(28)$

256 (132)

770 (121)

\section{Location of teams}

Ontario

$70 \%(16)$

$57 \%$ (4)

$73 \%(8)$

$100 \%(3)$

East of Ontario

$17 \%(4)$

$29 \%(2)$

$9 \%(1)$

0

West of Ontario

$13 \%(3)$

$11 \%(1)$

$18 \%(2)$

0

Years of operation

$<5$ years
$5-15$ years
$16-25$ years
$>25$ years
Number of student volunteers

0-20

21-40

41-60

61-80

\section{Dispatched through 9-1-1}

Dispatched via (could select multiple options)

Campus police or security

$87 \%(20)$

$43 \%(10)$

$91 \%(21)$

Approached at event

$$
\begin{aligned}
& 35 \%(8) \\
& 17 \%(4) \\
& 30 \%(7) \\
& 17 \%(4)
\end{aligned}
$$

$\begin{array}{cc}9 \%(2) & 29 \%(2) \\ 39 \%(9) & 43 \%(3) \\ 43 \%(10) & 29 \%(2) \\ 9 \%(2) & 0\end{array}$

$71 \%(5)$
0
$29 \%(2)$
0

$18 \%(2)$

$27 \%(3)$

$45 \%(5)$

$9 \%(1)$

0
0
0
$00 \%(3)$

Response method (could select multiple options)

\begin{tabular}{lcccc} 
On foot & $100 \%(23)$ & $100 \%(7)$ & $100 \%(11)$ & $100 \%(3)$ \\
Bicycle & $13 \%(3)$ & $14 \%(1)$ & $9 \%(1)$ & $33 \%(1)$ \\
Vehicle operated by team & $17 \%(4)$ & $29 \%(2)$ & $9 \%(1)$ & $33 \%(1)$ \\
Vehicle operated by security & $17 \%(4)$ & $29 \%(2)$ & $18 \%(2)$ & 0 \\
Patients approach team members & $91 \%(21)$ & $86 \%(6)$ & $91 \%(10)$ & $100 \%(3)$ \\
\hline
\end{tabular}

Notes: Two teams, University of Toronto (St. George) and St. Francis Xavier University, did not provide call volumes for either year, so they were not stratified by volume and are only included in the Total column.

IQR: interquartile range; SD: standard deviation 
the community. Departmental funding and institutional grants were each used by six teams (26\%). Grants from outside the university or college were used by four teams (17\%). One team $(4 \%)$ held fundraisers and one team (4\%) collected money from their volunteer responders to support team operations.

\section{Responder compensation}

All teams reported that all of their medical responders were volunteers. Five teams (21\%) provided honorariums or hourly wages to members with specific administrative or leadership responsibilities (Table 5).

\section{Discussion}

Canadian campus emergency medical response teams are operating at many universities and colleges across Canada, although they fall predominantly within in Ontario, which is home to some of the oldest teams. These teams, staffed with student volunteer medical responders, vary in size, services offered, level of training, mode of dispatch, and call volume among other metrics. CEMRT oncall responders are geographically close to the individuals they are called to assist, familiar with the campus buildings, and a prior survey of campus-based EMS services indicated an average

Table 4: Training information for campus emergency medical response teams

\begin{tabular}{lcccc}
\hline & Total & $\begin{array}{c}\text { Low volume } \\
(\leq \mathbf{1 0 0} \text { calls/year })\end{array}$ & $\begin{array}{c}\text { Medium volume } \\
(\mathbf{1 0 0 - 5 0 0} \text { calls/year })\end{array}$ & $\begin{array}{c}\text { High volume } \\
(>\mathbf{5 0 0} \text { calls/year })\end{array}$ \\
\hline Level of training* & & & & \\
Standard First Aid (SFA) & $9 \%(2)$ & $14 \%(1)$ & $9 \%(1)$ & 0 \\
First Responder (FR) & $48 \%(11)$ & $57 \%(4)$ & $45 \%(5)$ & $33 \%(1)$ \\
Mixed SFA/FR & $13 \%(3)$ & $14 \%(1)$ & $18 \%(2)$ & 0 \\
Emergency Medical Responder (EMR) & $4 \%(1)$ & 0 & 0 & $33 \%(1)$ \\
Mixed SFA/FR/EMR & $4 \%(1)$ & 0 & $18 \%(1)$ & 0 \\
Mixed FR/EMR & $9 \%(2)$ & 0 & 0 & $33 \%(1)$ \\
Mixed FR/EMR/Higher & $9 \%(2)$ & $14 \%(1)$ & & $100 \%(3)$ \\
& & & $55 \%(6)$ &
\end{tabular}

\section{Teams carrying symptom relief medication}

$\begin{array}{lcccc}\text { Aspirin } & 39 \%(9) & 57 \%(4) & 18 \%(2) & 100 \%(3) \\ \text { Diphenhydramine } & 9 \%(2) & 0 & 9 \%(1) & 33 \%(1) \\ \text { Epinephrine } & 57 \%(13) & 57 \%(4) & 45 \%(5) & 100 \%(3) \\ \text { Oral glucose } & 70 \%(16) & 71 \%(5) & 64 \%(7) & 100 \%(3) \\ \text { Salbutamol/albuterol } & 17 \%(4) & 14 \%(1) & 9 \%(1) & 67 \%(2) \\ \text { Naloxone } & 52 \%(12) & 71 \%(5) & 45 \%(5) & 67 \%(2) \\ \text { Pain management } & 0 & 0 & 0 & 0 \\ \text { Nitroglycerin (assist with patient's med- } & 39 \%(9) & 57 \%(4) & 18 \%(2) & 67 \%(2) \\ \text { ication) } & 4 \%(1) & 14 \%(1) & 0 & 0 \\ \text { Nitroglycerin (carried by team) } & & & \end{array}$

\section{Teams with additional medical equipment}

\begin{tabular}{lcccc} 
AED & $91 \%(21)$ & $86 \%(6)$ & $91 \%(10)$ & $100 \%(3)$ \\
Oxygen & $83 \%(19)$ & $71 \%(5)$ & $82 \%(9)$ & $100 \%(3)$ \\
Glucometer & $22 \%(5)$ & $29 \%(2)$ & $9 \%(1)$ & $67 \%(2)$ \\
IV start & $4 \%(1)$ & $14 \%(1)$ & 0 & 0 \\
\hline
\end{tabular}

Notes: Two teams, University of Toronto (St. George) and St. Francis Xavier University, did not provide call volumes for either year, so they were not stratified by volume and are only included in the Total column.

* One team, University of Toronto (St. George), indicated mixed training levels but did not specify the mix and is therefore not included under level of training.

AED: automated external defibrillator; IV: intravenous line 
Table 5: Administrative details of campus emergency medical response teams

\begin{tabular}{lcccc}
\hline & Total & $\begin{array}{c}\text { Low volume } \\
(\leq \mathbf{1 0 0} \text { calls/year })\end{array}$ & $\begin{array}{c}\text { Medium volume } \\
(\mathbf{1 0 0 - 5 0 0} \text { calls/year })\end{array}$ & $\begin{array}{c}\text { High volume } \\
(>\mathbf{5 0 0} \text { calls/year })\end{array}$ \\
\hline $\begin{array}{lcccc}\text { Response services during academic year (September to April) } \\
\text { Any event-based coverage }\end{array}$ & & & & \\
Event-based only & $74 \%(17)$ & $71 \%(5)$ & $64 \%(7)$ & $100 \%(3)$ \\
Select on-call hours & $26 \%(6)$ & $43 \%(3)$ & $18 \%(2)$ & 0 \\
$24 / 7$ on-call; excluding holidays & $30 \%(7)$ & $29 \%(2)$ & $36 \%(4)$ & 0 \\
$24 / 7$ on-call; including holidays & $22 \%(5)$ & $14 \%(1)$ & $27 \%(3)$ & $33 \%(1)$ \\
& $22 \%(5)$ & $14 \%(1)$ & $18 \%(2)$ & $67 \%(2)$ \\
Summer services provided & & & & $100 \%(3)$
\end{tabular}

Affiliated campus entities

$\begin{array}{lcccc}\text { Student council or union } & 26 \%(6) & 43 \%(3) & 18 \%(2) & 0 \\ \text { Health services } & 9 \%(2) & 0 & 9 \%(1) & 33 \%(1) \\ \text { Police, security, or emergency management } & 30 \%(7) & 14 \%(1) & 36 \%(4) & 33 \%(1) \\ 2 \text { of the above } & 26 \%(6) & 29 \%(2) & 27 \%(3) & 33 \%(1) \\ 3 \text { of the above } & 9 \%(2) & 14 \%(1) & 9 \%(1) & 0\end{array}$

Funding source (could select multiple options)

$\begin{array}{lcccc}\text { General student fee } & 65 \%(15) & 57 \%(4) & 82 \%(9) & 67 \%(2) \\ \text { Providing first aid courses } & 39 \%(9) & 29 \%(2) & 45 \%(5) & 67 \%(2) \\ \text { Departmental funding } & 26 \%(6) & 29 \%(2) & 27 \%(3) & 33 \%(1) \\ \text { Institutional grants } & 26 \%(6) & 29 \%(2) & 18 \%(2) & 33 \%(1) \\ \text { Non-institutional grants } & 17 \%(4) & 29 \%(2) & 9 \%(1) & 0 \\ \text { Fundraisers } & 4 \%(1) & 0 & 9 \%(1) & 0 \\ \text { Volunteer registration fee } & 4 \%(1) & 14 \%(1) & 0 & 0\end{array}$

\section{Team member compensation}

Medical responders

Student leaders or members assigned specific administrative tasks

0

$21 \%(5)$
0

$14 \%(1)$
0

$18 \%(2)$
0

$67 \%(2)$

Note: Two teams, University of Toronto (St. George) and St. Francis Xavier University, did not provide call volumes for either year, so they were not stratified by volume and are only included in the Total column.

response time of $<3$ minutes. ${ }^{9}$ We found that $91 \%$ of Canadian CEMRTs are trained and equipped to provide early defibrillation, $70 \%$ carry oral glucose, $57 \%$ carry epinephrine, and $52 \%$ carry naloxone indicating that CEMRT responders are trained and equipped to provide lifesaving care with rapid response times.

Only three Canadian CEMRTs, all providing 24/7 on-call response, had greater than 500 calls per year. This represents a small fraction of the number of calls for paramedic services operating within these communities. For example, a 2018 report from Middlesex London Paramedic Service, with a total catchment area population of approximately 400,000 including the population of Western University $\left(30,700\right.$ students and 4000 staff and faculty) ${ }^{18}$ indicated that they responded to 60,840 calls for service with patient carry potential. ${ }^{19}$ Often, an acute increase in call volume occurs during campus events such as concerts, which are staffed by the majority of CEMRTs (74\%). For cities that operate a fixed number of ambulances, this can put extreme short-term demands on local EMS systems. CEMRTs' ability to triage calls may allow paramedics to respond only to those calls that require higher levels of care, easing operational strain and reducing costs for local paramedic services and municipalities. Evaluating this hypothesis is an interesting avenue for future study. However, a small private college in the United States observed an increase in the number of alcohol-related transports to a local emergency department after implementing campus-based EMS. ${ }^{16}$ The authors of the 
study attributed this increase to a higher level of social trust in peer responders resulting in an increase in reporting behaviour. Willingness to report is essential to meeting the clinically necessary level of medical response for any potential patient. ${ }^{20,21}$ This role for CEMRTs as trusted peers has also been identified as important in campus responses to sexual assaults and mental health emergencies. ${ }^{10,22}$

Previous surveys have looked at CEMRTs across North America. ${ }^{9,13}$ King et al. ${ }^{13}$ surveyed college and university administrators to identify teams in the United States and Canada in the early 1990s. The authors reported variation in training level, with $79 \%$ of teams indicating at least some responders with first aid certifications, $60 \%$ of teams indicating at least some responders with Emergency Medical Technician (EMT)-Basic level training (approximately analogous to Canadian Red Cross EMR), and $40 \%$ of teams with at least some responders with EMT-Paramedic level training (approximately analogous to PCP training in Ontario). Further, they investigated the method of activation of CEMRTs. Activation through campus police was used by $76 \%$ of teams, which is similar to our findings for Canadian CEMRTs at $87 \%$. Fisher et al. ${ }^{9}$ surveyed teams registered with the NCEMSF in 2002 and reported a response from one Canadian CEMRT. They identified training level, response type, hours of operation, departmental affiliation, funding, and responder compensations. ${ }^{9}$ Similar to King et al., ${ }^{13}$ Fisher et al. ${ }^{9}$ reported most teams being trained at the level of EMT-Basic (66\%), but a lower proportion of teams were operating with advanced or paramedic-level training. Consistent with the general public expansion of AED training and availability over the past 20 years, our study found that $91 \%$ of Canadian CEMRTs carried an AED compared to 70\% of CEMRTs analysed in Fisher et al. ${ }^{9}$

One major limitation of this study was the reliance on self-reported data from individual teams, so the information collected may be subject to reporting biases. When information was unclear, we were able to follow-up with respondents to clarify their responses, hopefully improving the accuracy of the reports. Additionally, it is possible that teams were missed in this survey since most but not all Canadian CEMRTs are registered with ACERT or NCEMSF. In our study, five such teams were contacted and three submitted responses to the survey. These teams were identified through the authors' involvement in the Canadian CEMRT community. Finally, we did not investigate other roles CEMRTs may play on their campuses, including participation in health education campaigns (e.g., Stop the Bleed) or disaster scenarios. This would be important to characterize in future work.

In conclusion, this study is the first attempt at specifically characterizing Canadian CEMRT organizations and the services they provide. This is important to elucidate the communities in which these teams operate and to foster collaboration between local paramedic services and CEMRTs. This information can serve to inform providers of the capabilities of CEMRTs so that hospitals, paramedic services, and universities/colleges can ensure their communities are receiving the best care. This data may also help inform other university and college campuses of CEMRTs and the role they can play on Canadian campuses. This study identified many CEMRTs operating across Canada with significant variation in training level, capabilities, call volume, and administrative operations. This variability is likely due to CEMRTs aiming to meet the specific needs of their unique campuses. Further investigation is needed to characterize the types of incidents these teams respond to and whether there are any savings in costs or resources for the local emergency services. Establishing the efficacy of CEMRTs is the next step in identifying their role in the campus community.

\section{References}

1. Balodis IM, Potenza MN, Olmstead MC. Binge drinking in undergraduates: relationships with sex, drinking behaviors, impulsivity, and the perceived effects of alcohol. Behav Pharmacol. 2009; 20(5-6):518-526.

2. Caamano-Isorna F, Moure-Rodriguez L, Doallo S, Corral M, Rodriguez Holguin S, Cadaveira F. Heavy episodic drinking and alcohol-related injuries: An open cohort study among college students. Accid Anal Prev. 2017; 100:23-29.

3. Moure-Rodriguez L, Caamano-Isorna F, Doallo S, et al. Heavy drinking and alcohol-related injuries in college students. Gac Sanit. 2014; 28(5):376-380.

4. Mundt MP, Zakletskaia LI, Fleming MF. Extreme college drinking and alcohol-related injury risk. Alcohol Clin Exp Res. 2009; 33(9):1532-1538.

5. Arthur-Banning SGJ, D; Black, K; Mkumbo, P. An epidemiology of sport injury rates among campus recreation sport programs. Rehabilitation Science. 2018; 3(2):38-42.

6. Byington KW, Schwebel DC. Effects of mobile Internet use on college student pedestrian injury risk. Accid Anal Prev. 2013; 51:78-83.

7. Carey KB, McClurg AJ, Bolles JR, Hubbell SJ, Will HA, Carey MP. College student drinking and ambulance utilization. J Public Health Manag Pract. 2009; 15(6):524-528

8. McLaughlin MP. Alcohol-associated illness and injury and ambulance calls in a midwestern college town: a four-year retrospective analysis. Prehosp Emerg Care. 2010; 14(4):485-490.

9. Fisher J, Ray A, Savett SC, Milliron ME, Koenig GJ. Collegiate-based emergency medical services (EMS): a survey of EMS systems on college campuses. Prehospital and disaster medicine. 2006; 21(2):91-96.

10. Friedman NMG, Dingler BJ, Gorstein LN, Epstein JA. Implementation of a Mental Health Task Force in a collegiate-based emergency medical services organization. Journal of American College Health. 2019:1-5.

11. Jeffery RM, Dickinson L, Ng ND, DeGeorge LM, Nable JV. Naloxone administration for suspected opioid overdose: An expanded scope of practice by a basic life support collegiate-based emergency medical services agency. Journal of American College Health. 2017;65(3):212-216.

12. Stefos KA, Nable JV. Implementation of a high-performance cardiopulmonary resuscitation protocol at a collegiate emergency medical services program. Journal of American College Health. 2016; 64(4):329-333.

13. King BR, Zachariah BS, Cone DC, Clark P. A survey of emergency medical services systems on college and university campuses. Prehospital and disaster medicine. 1996; 11(4):265-269.

14. Paramedic Association of Canada. National Occupational Competency Profile for Paramedics. Ottawa. October 2011. https://paramedic.ca/uploaded/web/documents/2011-10-31-Approved-NOCP-English-Master.pdf. Accessed 2020. 
15. Canadian Red Cross Society. Emergency Care for Professional Responders. 2018.

16. Rosen JB, Olson MH, Kelly M. Collegiate-based emergency medical service: impact on alcohol-related emergency department transports at a small liberal arts college. Journal of American College Health. 2012; 60(3):263265 .

17. Canadian Red Cross Society. First Aid Program Standards. Alberta 2017. https://www.redcross.ca/crc/documents/What-We-Do/First-Aid-and-CPR/ FA_-ProgramStandards_July2017_EN.pdf. Accessed 2020.

18. Western University. Facts and Figures 2018-2019. https://www.uwo.ca/ about/whoweare/facts.html. Published 2019. Accessed 2019.

19. Middlesex London Paramedic Service. 2018 Performance Report. London, Ontario 2018. https://www.mlems.ca/2018_MLPS_Performance_Report. pdf. Accessed 2019.

20. Oster-Aaland L, Lewis MA, Neighbors C, Vangsness J, Larimer ME. Alcohol poisoning among college students turning 21: do they recognize the symptoms and how do they help? J Stud Alcohol Drugs Suppl. 2009; (16):122-130.

21. Tobin KE, Davey MA, Latkin CA. Calling emergency medical services during drug overdose: an examination of individual, social and setting correlates. Addiction. 2005; 100(3):397-404.

22. Gorstein LN, Riviello RJ. Drug-facilitated sexual assualt: Implications for Collegiate-based Emergency Medical Services. Journal of Collegiate Emergency Medical Services. 2019; 1(1):25-34.

\section{Supplementary Materials}

Appendix: Full Survey (available online)

Author Affiliations: From School of Medicine, New York Medical College - in Valhalla, NY, USA (E.A.F.). From Student Health Services, Western University - in London, ON, Canada (L.A.G.). From Department of Anatomy and Cell Biology, Schulich School of Medicine and Dentistry, Western University - in London, ON, Canada (A.D.R.). From London InterCommunity Health Centre; Department of Family Medicine, Schulich School of Medicine and Dentistry, Western University - in London, ON, Canada (A.M.S.). From Ivey Business
School; Department of Epidemiology \& Biostatistics, Schulich School of Medicine and Dentistry, Western University - in London, ON, Canada (L.E.C.).

Address for Correspondence: Lauren E. Cipriano, PhD | Email: lcipriano@ivey. uwo.ca | Address: Ivey Business School, 1255 Western Road, London, Ontario, Canada N6A 3K7

Conflicts of Interest/Funding Sources: By the JCEMS Submission Declaration Form, all authors are required to disclose all potential conflicts of interest and funding sources. All authors declared that they are former volunteers on a CEMRT. EAF volunteers with NCEMSF. AMS and LAG are current medical directors and LEC provides training and education. The authors declared that this work was supported in part by the David G. Burgoyne Faculty Fellowship (LEC).

Authorship Criteria: By the JCEMS Submission Declaration Form, all authors are required to attest to meeting the four ICMJE.org authorship criteria: (1) Substantial contributions to the conception or design of the work; or the acquisition, analysis, or interpretation of data for the work; AND (2) Drafting the work or revising it critically for important intellectual content; AND (3) Final approval of the version to be published; AND (4) Agreement to be accountable for all aspects of the work in ensuring that questions related to the accuracy or integrity of any part of the work are appropriately investigated and resolved.

Prior Presentation: The data contained within this paper has previously been presented at the Canadian Association of Emergency Physicians conference on May 27, 2019 in Halifax, Nova Scotia, Canada.

Submission History: Received April 25, 2020; accepted for publication December 9, 2020.

Published Online: December 31, 2020

Published in Print: December 31, 2020 (Volume 3: Issue 2)

Reviewer Information: In accordance with JCEMS editorial policy, Original Research manuscripts undergo double-blind peer-review by at least two independent reviewers. JCEMS thanks the anonymous reviewers who contributed to the review of this work.

Copyright: ( 2020 Formosa, Grainger, Roseborough, Sereda \& Cipriano. This is an open access article distributed under the terms of the Creative Commons Attribution 4.0 International (CC BY 4.0) License, which permits unrestricted use, distribution, and reproduction in any medium, provided the original author and source are credited. The full license is available at: https://creativecommons.org/ licenses/by/4.0/

Electronic Link: https://doi.org/10.30542/JCEMS.2020.03.02.04 